\title{
Total Diz Artroplasti Ameliyatının Nadir Bir Komplikasyonu: Femur Boyun Kırığı
}

\author{
A Rare Complicationof Total Knee Arthroplasty Surgery: Femoral Neck Fracture A Case Report
}

${ }^{1}$ Ebru Atalar, ${ }^{2}$ Tolga Tolunay

(ii)

${ }^{1}$ Ankara Sehir Hastanesi Romatoloji Kliniği, Ankara, Türkiye

${ }^{2}$ Gazi Üniversitesi Tip Fakültesi Ortopedi ve Travmatoloji Anabilim Dalı, Ankara, Türkiye

\section{Correspondence:}

Ebru ATALAR

Ankara Şehir Hastanesi Romatoloji Kliniği, Ankara, Türkiye

e-mail: atalarebrudr@yahoo.com

\section{Özet}

Tüm dünyada yaşlı popülasyonun artmasına bağlı olarak gonartroz gibi dejeneratif eklem hastalıkları önemli bir toplum sağlığı problemi haline gelmiştir. Bu hastalığın son basamak tedavi metodu diz artroplasti ameliyatıdır. Femur boyun kırıkları bu ameliyatların nadir görülen ve geç teşhis edilen komplikasyonlarından biridir. Hastaların başlıca şikâyetleri, uzamış ameliyat sonrası ağrı ve yürüme zorluğudur. Erken tanı koyulması durumunda vida ile kırık sabitlenerek kemik deplasmanı önlenebilir. Fakat, bu hastalar sıklıkla geç tanı alırlar ve kalça artroplastisi ameliyatı ile tedavi edilirler. Erken tanıda en etkili yöntem kalça ekleminin manyetik rezonans görüntülemesidir. Bu olgu sunumunda total diz artroplasti ameliyatı sonrası ipsilateralfemur boyun kırı̆ğ gelişen hasta tartışılmıştır.

Anahtar Kelimeler: Femur boyunkırıkları; total dizartroplastisi; ameliyatsonrasıkomplikasyonlar; kronikağrı

\section{Abstract}

Degenerative joint diseases such as gonarthrosis have become an important public health problem due to the increase in the elderly population all over the world. The last step treatment method of this disease is knee arthroplasty surgery. Femoral neck fractures are one of the rare and late diagnosed complications of these surgeries. The main complaints of the patients are prolonged postoperative pain and difficulty in walking. In case of early diagnosis, bone displacement can be prevented by fixing the fracture with screws. However, these patients are often diagnosed late and are treated with hip arthroplasty surgery. The most effective method in early diagnosis is magnetic resonance imaging of the hip joint. In this case report, a patient who developed an ipsilateral collum femoris fracture after total knee arthroplasty surgery is discussed.

Keywords: Femoralneckfractures; total kneearthroplasty; postoperativecomplications; chronicpain 


\section{Giriș}

Gonartroz ileri yaşlarda oldukça sik görülen morbidite sebeplerinden olup, ileri evre gonartrozda cerrahi tedavi seçenekleri gündeme gelmektedir. $\mathrm{Bu}$ amaçla yapılan total diz artroplasti ameliyatlarının sonuçları oldukça yüz güldürücüdür. Bununla birlikte bu ameliyatların enfeksiyon, tromboemboli, refleks sempatik distrofi, periprostetik kırık, aseptik gevşeme gibi komplikasyonları olabilmektedir (1). Ameliyat sonras1 zamanla azalmayan ağr1 olması durumunda, ameliyat bölgesi ile alakalı olarak, enfeksiyon, aseptik gevşeme gibi durumlar öncelikle araştırılmalı ayrıca da yansıyan ağrılar akılda tutulmalıdır. Diz artroplati ameliyatı ile ilişkili femur boyun kırığı oldukça nadir görülen komplikasyonlardan olup ameliyat sonras1 uzamış kasık ve inguinal bölge ağrısı ile kendini gösterir (2). Bu olgu sunumunda diz artroplasti ameliyatı sonrası gecikmiş tanı alan ve ameliyat komplikasyonu olarak femur boyun kırığı gelişen hasta tartışılmıştır.

\section{Olgu sunumu}

80 yaşında erkek hasta sağ total diz artroplastisi sonrası başlayıp devam eden aynı taraf uyluk ağrıs1 ve ekstremite üzerine basamama şikayeti ile başvurdu. Ameliyat sonrası dönemde hasta koltuk değneği ile yürümek zorunda kaldığını, hiçbir şekilde yardımsız yürüyemediğini ifade etti. Hastanın öyküsünden uzamış ağrılarının cerrahi işleme bağlı normal ameliyat sonrası ağrı olarak değerlendirildiği öğrenildi. Uzamış ağrı etiyolojisini araştırmak üzere başka hastaneye başvuran hastanın pelvis bilgisayarlı tomografi (BT) tetkikinde sağ kalça ekleminde deformasyon dişında patolojik bulgu saptanmamış ve 3. basmak sağlık merkezine sevk edilmiş. Ameliyat sonrası 18. ayda tarafımıza başvuran hastanın ameliyattan sonra düzelmeyen ağrısının ve yürüme güçlüğünün olduğu, son 6 aydır yürümesinin iyice zorlaştı̆̆ Hastanın ameliyatı takip eden ikinci günde koltuk değneği yardımı ile mobilize edildiği yürürken tam ağrılık vermesine izin verildiği öğrenildi. Fakat hastanın ameliyat sonrası dönemde koltuk değneği yardımı olmadan ve sağ alt ekstremitesine tam ağırlık vererek yürüyemediği, son aylarda koltuk değneği yardımına rağmen yürümesinin iyice ağrılı ve zorlu olduğu öğrenildi. Hastanın bilinen steroid kullanım öyküsü yoktu. Romatolojik yönden değerlendirilen hastada romatizmal hastalık saptanmadi. Fizik muayenesinde diz eklem hareket açıklığının normal ve hareketlerin hafif ağrilı olduğu, kalça eklemi hareketlerinin ağrı nedeniyle kısıtlı olduğu tespit edildi. Hastanın ameliyat öncesi radyolojik görüntülerinin incelenmesinde, varus deformitesinin eşlik ettiğ $i$ gonartroz görüldü. Bununla birlikte ameliyat öncesi döneme ait uygun aks grafisi olmadığı için sağlıklı bir şekilde varus derecesi ölçümü yapılamadı. Diz artroplasti ameliyatı sonrası 18. ayda hastanemizde çekilmiş olan AP diz grafisinde ise protezi ile alakalı sorun olmadiğ 1 (Şekil 1), pelvis ön arka grafisinde ise femur başının izlenmediği ve asetabulum superolateralinin deforme olduğu görüldü (Şekil 2). Rutin kan tetkiklerinde Alkalen fosfataz 60 U/L (43-115) CRP: $8.90 \quad \mathrm{mg} / \mathrm{L} \quad(0-5)$ Sedimentasyon $15 \mathrm{~mm} / \mathrm{h}$ (0-15), RF: 10.73 türbidimetrik (0-14) olarak saptandı. Kalça eklemi manyetik rezonans görüntüleme (MRG) tetkikinde femur başının fragmante halde olduğu, asetabulumun içinde yumuşak doku varlığ femur boynunun basis1 ile asetabulum superolateralinin deforme olduğu görüldü (Şekil 3). Hastanın başvuru sırasında getirdiği tetkiklerin incelenmesi sonucunda başka merkezde ameliyatını takiben 7 . ayda çekilmiş olan AP lomber grafisinde sağ femur başının skleroze olduğu görüldü (Şekil 4). Diz artroplasti ameliyatını takip eden 18 . ayda hasta tanı ve tedavi amacı ile ameliyata alındı. Ameliyat sırasında, kalça ekleminde efüzyon olduğu, femur başının ayrı ve küçük bir parça olarak kaldığı (Şekil 5), femur boyun basısına bağlı olarak asetabulum superolateralinin yeniden şekillendiği görüldü (neoasetabulum) (Şekil 6). Bununla birlikte femur baş1 ve femur boynunda tümör veya enfeksiyon görüntüsü olmadığı görüldü. Parsiyel kalça artroplastisi yapılması planlanan hastanın asetabulumundaki deformasyon sebebiyle bu işlemi yapılamadı. Kırılmış ve ayrı parça olarak kalan femur başının greft kullanımı için uygun olduğu gözlendi. Serbest olan femur baş1 şekillendirildikten sonra asetabulum superolateraline greft olarak yerleştirilerek vidalar ile sabitlendi. Daha sonra femoral komponent hazırlık aşamasına geçildi. Bu sırada trokanterik ayrilma meydana geldi. Femoral komponent yerleştirilip kalça eklemi redükte edildikten sonra ayrılan trokanter majör kablolar ile sabitlendi. (Şekil7). 


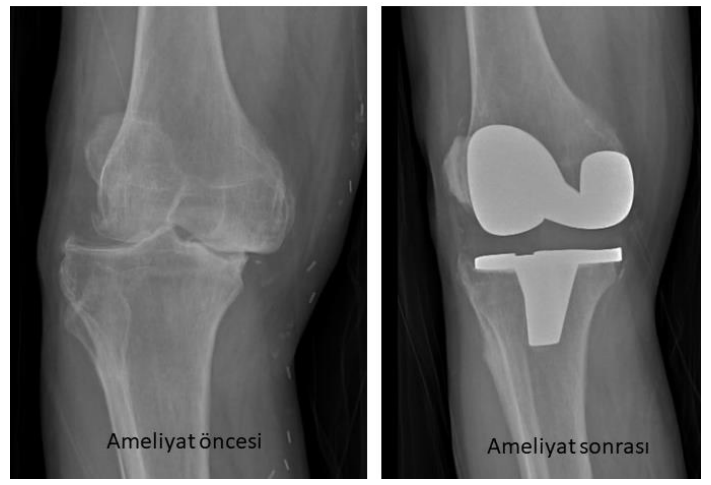

Şekil 1. Ameliyat öncesi ve ameliyat sonrası diz ön arka grafileri

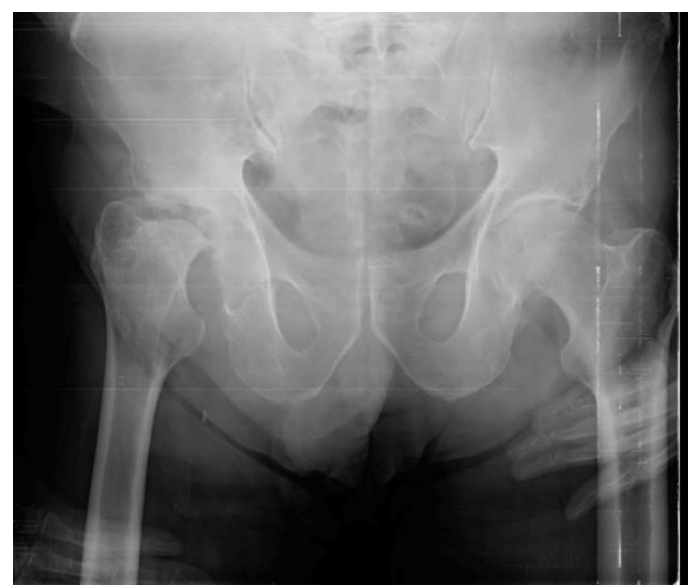

Şekil 2. Pelvis ön arka grafisinde sağ femur başının izlenmediği ve asetabulumun superolateralinin aynı zamanda femur boynunun deforme olduğu görülüyor.

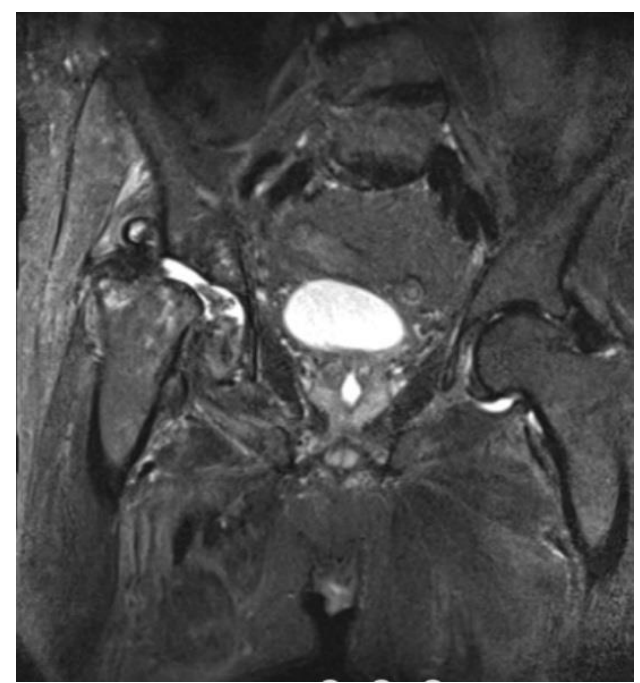

Şekil 3. Çekilmiş olan koronal MRG kesitinde femur başının fragmante halde olduğu, asetabulumun içinde yumuşak doku varlığı, femur boynunun basısı ile asetabulum superolateralinin deforme olduğu görülüyor. 


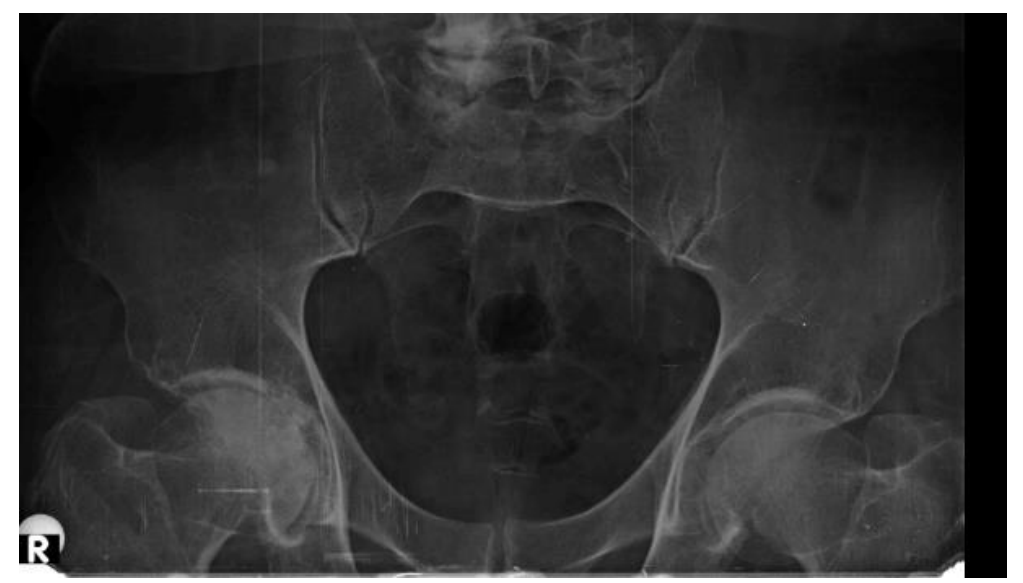

Şekil 4. Merkezimize başvurmadan 7 ay önce çekilmiş olan AP lomber grafinin görüntüleme alanına giren sağ femur başında belirgin skleroz görülüyor.

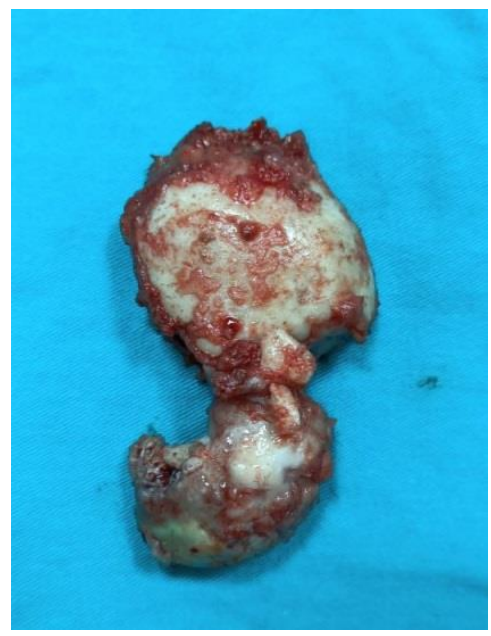

Şekil 5. Ameliyat sırasında femur başının kalça eklemi içinde serbest ve atrofiye uğramış halde olduğu görüldü.

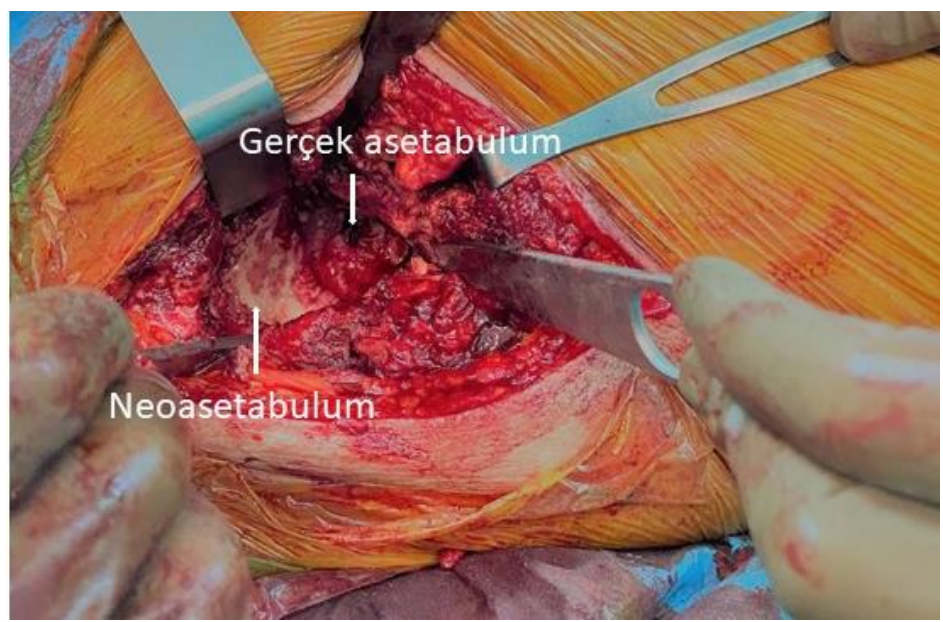

Şekil 6. Asetabulum superolateralinin femur boynunun basısına bağlı olarak deforme olduğu ve yeniden şekillendiği görüldü. 


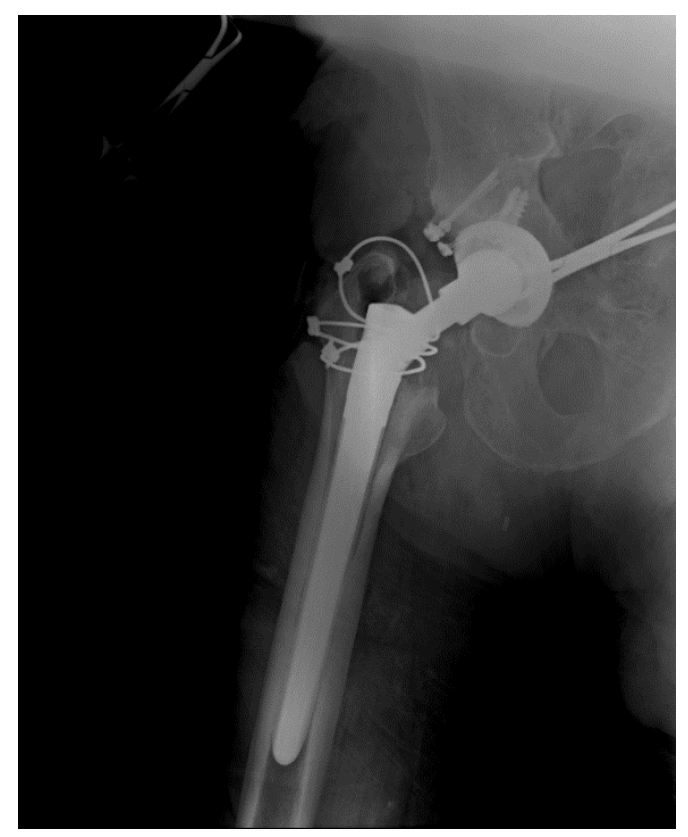

Şekil 7. Serbest olan femur başı greft olarak kullanılarak hastaya total kalça artroplasti ameliyatı yapıldı.

\section{Tartışma ve sonuç}

Femur boyun stres kırıkları, normal kemik fizyolojisine sahip olan bireylerde tekrarlayan yorucu aktiviteler sonucu veya osteoporotik bireylerde normal fizyolojik yüklenmeler sonucunda meydana gelebilir. $\mathrm{Bu}$ durumlarda kemiğin tamir mekanizmaları mikrokırıkları tamir etmekte yetersiz kalır ve zamanla tam kırık meydana gelir $(2,3)$.

Diz artroplasti ameliyatını takip eden dönemde görülebilen femur boyun stres kırıkları bu ameliyatların oldukça nadir ve geç tanı alan komplikasyonlarındandır. Femur boynu haricinde, pubik ramus, tibia, fibula ve femur proksimalinde de bu tarz stres kırıkları görülebilir (4-8). Bu tarz kırıkların oluşum mekanizması tam olarak bilinmese de altta yatan immobilite ilişkili osteoporoz ve diz artroplasti ameliyat1 sonrasında, alt ekstremite aksının değişmesinin etkili olduğu kabul edilmektedir. Bu şekilde proksimal femur korteksinde yoğunlaşan gerilme ve kompresif kuvvetleri, yetmezlik kırığına yol açabilir $(8,9)$. Varus deformitesinin belirgin olduğu, ileri gonartrozu olan hastalarda ameliyat sonrası dönemde yük aksının değişmesi sonucu, distraksiyon kuvvetleri femur boynunun superior korteksinde yoğunlaşır ve bu bölgede varus yüklenmesine neden olur. Tekrarlayıcı varus yüklenmeleri ise stres / yetmezlik kırığına sebep olur. Bizim hastamızın ameliyat öncesi diz grafisinde de varus deformitesinin olması dikkat çekicidir. Diz protezi ameliyatları öncesinde ve sonrasında uygun aks grafilerinin çekilerek varus derecesinin ve sonrasinda elde edilen düzeltme derecesinin tespit edilmesi bu tarz komplikasyonların önlenmesi açısından önemli olabilir. Bizim hastamızda ameliyat öncesi ve sonrasına ait aks grafilerinin olmaması sebebiyle diz varus derecinde elde edilen düzelme miktarı tespit edilememiştir. Bunun haricinde romatoid artrit, steroid kullanımı, menteşeli protez kullanımı da risk faktörleri arasında kabul edilmektedir (9).

Hastaların geç tanı almasının sebebi, henüz instabilite gelişmemiş ve deplase olmamış kırığg bağlı kasık ve uyluk ağrısının, uzamış ameliyat sonras1 ağr1 olarak yorumlanmas1 ve hastaların ameliyat sonrası dönem ile alakalı travma öyküsünün olmamasıdır (8-10). Stres kırığı tanısı bu sebeple geç koyulmakta (ortalama 9 ay) bazen bu süre 33 aya kadar uzayabilmektedir (9). Bizim olgumuza olduğu gibi, ameliyatı takip eden erken dönemde femur proksimaline yönelik çekilmiş olan AP pelvis grafilerinde kırı hattı görülemeyebilir. Şüpheli durumlarda kemik sintigrafisi tanıyı doğrulamada yardımcı olur. Bununla birlikte bazı olguları teşhis etmekte kemik sintigrafisi yetersiz kalabilmekte, erken tanıyı koymada en hassas yöntemin MRG olduğu bildirilmektedir (11,12). Bizim olgumuzda da MRG ile tanı doğrulandı. Fakat MRG çekilme sebebi kırık tanısını doğrulamaktan ziyade ön arka grafide asetabulum ve femur başında 
görülen deforme görüntünün enfeksiyon, romatizmal hastalı veya tümöral bir oluşumla alakalı olup olmadığını değerlendirmek içindi. MRG görüntüleri, belirtilen değişikliklerin enfeksiyon veya tümör ile alakalı olmayıp travmaya sekonder olduğunu düşündürdü. Hastaya tanı ve tedavi amacı ile cerrahi girişim uygulandı. Ameliyat içi görüntülerde kemik kalitesinin iyi olduğu, kitle, enfeksiyon bulgusu veya sinovial inflamasyon bulgusu olmadiğı ve femur boynunun asetabuluma kronik basis1 sonrası neoasetabulum geliştiği görüldü. Bizim hastamızın ilginç tarafı ameliyat sonrası dönemde fiziksel aktivitesinin devamlı düşük düzeyde kalması ve devamlı olarak koltuk değneği kullanması idi. Hastamızın bildirdiği travma öyküsü de yoktu. Hastanın tıbbi öyküsünden diz ameliyatı öncesi desteksiz yürüdüğü, ameliyat öncesine ait travma öyküsünün ve kasık ağrısının olmadığ1 öğrenildi. Her ne kadar varus deformitesindeki düzeltmeye bağlı olarak femur boynunda stresin arttığı bilinse de, hastanın koltuk değneğini bırakmadan mobilize olması bu stresin fazla olmadığını düşünmemize sebep olabilir. $\mathrm{Bu}$ durumda, ameliyat sirasında diz protezine ait femoral komponentin çakılarak yerleştirilmesi sırasında femur boynunda mikrokırıklar meydana gelip zamanla kırığın deplase olma ihtimalini göz ardı etmememiz gerekir. Her ne kadar literatür incelenmesinde bu durum net olarak belirtilmemiş olsa da, daha önce revizyon diz artroplastisi ameliyat sonras1 gelişmiş olan femur boyun stres kırığı olgusunda, ilk ameliyatta varus deformitesinin düzeltilmiş olduğu kabul edilirse, ameliyat sırasinda femoral komponentin çakılarak yerleştirilmesi, bizim düşüncemize göre de femur boynunda mikrokırık gelişebileceği hipotezini destekler (8).

Diz artroplasti ameliyatı sonrasında meydana gelebilen femur boyun kırıklarında, özellikle stres / yetmezlik kırıklarında ağrı uyluktan ziyade kasık / ingunal bölgededir. Şüpheli durumlarda yapılacak muayene ile kalça hareketlerinde kısıtll1ık ve kalça hareketi ile artan kasık ağrısı saptanabilir. Erken tanı ile kırık deplase hale gelmeden cerrahi olarak sabitlenebilir. Erken tanıda ise en güvenilir yöntem MRG tetkikidir.

\section{KAYNAKLAR}

1. Passias PG, Bono OJ, Bono JV. Total Knee Arthroplasty in Patients of Advanced Age: A Look at Outcomes and Complications. J Knee Surg 2020;33:1-7.

2. Robinson PG, Campbell VB, Murray AD, et al. Stress fractures: diagnosis and management in the primary care setting. $\mathrm{Br} J$ Gen Pract 2019;69:209-300.

3. Bhatnagar A, Kumar M, Shivanna D, et al. High Incidence of Stress Fractures in Military Cadets During Training: A Point of Concern. $J$ Clin Diagn Res 2015;9:RC01-3.

4. Smith MD, Henke JA. Pubic ramus fatigue fractures after total knee arthroplasty. A case report. Orthopedics 1988;11:315-7.

5. Kumm DA, Rack C, Rütt J. Subtrochanteric stress fracture of the femur following total knee arthroplasty. J Arthroplasty 1997;12:580-3.

6. Takai H, Kii S, Murayama M, et al. Ipsilateral stress fracture of the proximal fibula after total knee arthroplasty in a patient with severe valgus knee deformity on a background of Rheumatoid arthritis. Int J Surg Case Rep 2018;45:17-21.

7. Ozdemir G, Azboy I, Yilmaz B. Bilateral periprosthetic tibial stress fracture after total knee arthroplasty: A case report. Int $J$ Surg Case Rep 2016;24:175-8.

8. Atalar H, Aytekin MN, Gunay C, et al. Stress fracture of the femoral neck as a complication of revision arthroplasty of the knee: a case report. Acta Orthop Belg 2008;74:418-20.

9. Cakmak S, Mahiroğulları M, Kürklü $\mathrm{M}$, et al. Bilateral femoral neck stress fracture following bilateral total knee arthroplasty: a case report. Acta Orthop Traumatol Turc 2012;46:312-5.

10. Morinaga S, Ueshima K, Maruhashi Y, et al. Bilateral Stress Fractures of the Femoral Neck after Total Knee Arthroplasty: Importance of Early Diagnosis. Case Rep Orthop 2020 6;2020:3091693.

11. Keene JS, Lash EG. Negative bone scan in a femoral neck stress fracture. A case report. $\mathrm{Am}$ J Sports Med 1992;20:234-6.

12. Wen DY, Propeck T, Singh A. Femoral neck stress injury with negative bone scan. $J \mathrm{Am}$ Board Fam Pract 2003;16:170-4. 